\title{
Excelência na Produtividade: A Performance dos Jogadores de Futebol Profissional
}

\author{
Daniel Kroeff de Araujo Corrêa ${ }^{1}$ \\ Universidade Federal do Rio Grande do Sul \\ João Carlos Alchieri ${ }^{2}$ \\ Universidade do Vale do Rio dos Sinos, Universidade Federal do Rio Grande do Sul \\ Lúcia Regina Severo Duarte ${ }^{3}$ \\ Pontifícia Universidade Católica do Rio Grande do Sul \\ Marlene Neves Strey ${ }^{4}$ \\ Pontifícia Universidade Católica do Rio Grande do Sul
}

\begin{abstract}
Resumo
O presente artigo analisa os aspectos que influenciam a performance do jogador de futebol e os fatores contextuais relacionados. Com esse objetivo, fez-se um estudo entrevistando 2 ex-atletas, 2 jogadores que ainda atuam, 2 treinadores e 2 preparadores físicos - todos experientes e consagrados em suas profissões - para verificar quais são os fatores considerados importantes para a performance dos jogadores de futebol. Realizou-se análise de conteúdo sobre os dados das entrevistas. Constatou-se que muitos fatores envolvem o contexto que influencia o desempenho. Esses podem ser divididos em fatores psicológicos, físicos, técnicos e táticos e de suporte social oferecido ao jogador. A partir das categorias levantadas, estabeleceram-se as bases para construção de um questionário contendo os principais temas abordados pelos entrevistados, o qual será utilizado num estudo posterior.

Palavras-chave: Performance; futebol; psicologia esportiva.
\end{abstract}

Excelence on Production: The Performance of Professional Soccer Players

\begin{abstract}
The present article analyzes the factors that influence the performance of soccer players and the contextual factors related to their performance. In this study the following people were interviewed: 2 former-athletes, 2 players that are still active, 2 coaches and 2 physical trainers, all experienced and renowned. The article aims at verifying which are the factors considered important for the performance of soccer players. Content analysis was performed on the data of the interviews. Results show that many factors are related to the context that influences the performance. These can be divided in categories involving psychological, physical, technical and tactical factors; there were also factors that involve the social background offered to the player. From the categories raised, the basis for the development of a questionnaire involving the main subjects of the interviews was elaborated and will be used in a following study.
\end{abstract}

Keywords: Performance; soccer; sport psychology.

O futebol é o esporte mais popular do mundo. Possui papel fundamental na sociedade capitalista onde vivemos, movimentando trilhões de dólares por ano. Cada vez mais, esse esporte internacional ganha novos adeptos, aumentando a atenção da mídia e o interesse de uma infinidade de pessoas no mundo todo (Wahl, 1997).

Com toda essa influência dos meios de comunicação social, é natural que jovens antes anônimos, quando conseguem boas atuações tornem-se, repentinamente, famosos. O fato dos atletas deixarem de ser pessoas comuns para se tornarem públicas, vivenciando toda a

\footnotetext{
${ }^{1}$ Endereço para correspondência: Av. Anita Garibaldi, 2381/704, 90480-
} 201. Telefone: (51) 91527050, Fax: (51) 33287928.E-mail: dkac@uol.com.br riqueza propiciada pelo estrelato, provoca forte influência em suas personalidades. A fama, o dinheiro e o luxo desse esporte podem fazer os craques terem problemas em suas vidas privadas e isto alterar sua performance no campo.

Quando ingressam no milionário mundo do futebol, os jogadores passam a contar com uma preparação física, técnica e tática que evoluiu vertiginosamente nos últimos anos. Esses cuidados envolvem equipes de médicos, nutricionistas, massagistas, técnicos, fisioterapeutas, psicólogos, entre outras especialidades. Os clubes investem em um arsenal de estratégias para que seus atletas rendam o máximo e, por essa razão, exigem vitórias. Segundo Corrêa e Strey (1999), manter a imagem, a atuação e os resultados esperados acaba por se tornar um exercício 
estressante, principalmente porque o jogador acredita e, é levado a crer, que tudo depende dele, já que a nossa cultura individualista fomenta essa atitude autocentrada. Essa é uma das razões pelas quais muitos atletas passam por intenso sofrimento em sua profissão. Entender os fatores relacionados à performance pode auxiliar esses esportistas a terem um maior cuidado com a sua carreira, possibilitando assim uma evolução no nível de saúde e de bem-estar dessas pessoas.

Atualmente, os clubes estão aprendendo a valorizar os aspectos psicológicos do jogador e a necessidade de disciplina, conduta, responsabilidade e autoconfiança passou a ser fator importante na definição da contratação de um atleta. Não basta mais excelente técnica, preparo físico e habilidade dentro de campo, é preciso também ter consciência e maturidade dentro e fora dele nas suas ações.

Em toda ação, presente em um jogo de futebol, existe um envolvimento psíquico, sendo esse consciente ou não, mas a qualidade desse envolvimento terá fundamental importância no resultado da ação. Dividir uma bola com um adversário desperta no atleta sentimentos de posse, de levar vantagem, de triunfo, de competição. A partir da conscientização desses aspectos, a preparação atlética passou a envolver também objetivos afetivos (Venzon, 1998).

Existem muitos livros, revistas e jornais escritos sobre o futebol. São raras, no entanto, as publicações técnicocientíficas que buscam explicar os fenômenos relacionados ao desempenho esportivo dos jogadores. Com o objetivo de entender os fatores relacionados à performance dos atletas em campo, foi realizada uma pesquisa na qual foram entrevistados preparadores físicos, treinadores, ex-jogadores e jogadores de futebol profissional de grandes clubes da capital gaúcha. Para melhor contribuir ao entendimento desse tema, apresentamos a seguir uma breve revisão teórica sobre modelos de compreensão da performance esportiva e também sobre as variáveis que lhe estão associadas.

\section{Momento Psicológico e Performance}

O Momento Psicológico (MP) é seguidamente citado como uma das razões subjacentes ao sucesso e também ao insucesso no campo dos esportes (Eisler \& Spink, 1998). Existem modelos que buscam analisar a relação do MP com a performance. Momento é definido como uma alteração positiva ou negativa nos aspectos cognitivos, emocionais, fisiológicos e comportamentais, causada por um evento ou uma série de eventos. Essa alteração pode resultar em uma mudança na performance e no resultado da competição.O primeiro desses modelos é chamado Modelo Multidimensional (Multidimensional Model, Taylor \& Demick, 1994) é um modelo complexo, pois desdobra a análise da relação MP-performance em uma seqüência de eventos. O segundo, denominado Modelo Antecedente-consequência ${ }^{1}$ (The Antecedents-Consequences Model, Vallerand \& Colavecchio, 1988) é um modelo mais simples, do estilo causa e conseqüência.

Taylor e Demick (1994) propõem um modelo teórico chamado Modelo Multidimensional para explicar como o momento psicológico (MP) dos atletas influencia sua performance. A relação entre MP e performance pode ser analisada como uma seqüência de fatos. Tal seqüência é desencadeada por uma reação a um evento ou a uma série de eventos precipitadores como, por exemplo, quando um jogador recebe um passe de um companheiro (evento precipitador) e a melhor jogada que pode realizar nesse lance é driblar um adversário (reação ou resposta a esse evento). De acordo com essa resposta, o atleta faz uma avaliação de sua performance no lance como significativamente superior ou inferior a suas exigências subjetivas internas no contexto da situação. Dessa forma, o evento precipitador funciona como um catalisador que gera a percepção no desportista de seu MP. Esse evento é avaliado pelo atleta como positivo, se ele considerar sua performance no lance bem sucedida. Assim sendo, sentirá um aumento na autoconfiança, na emoção, na motivação, na atenção concentrada e na sensação de controle da jogada. Esse estado mental positivo, decorrente do sucesso no início do lance, resultará em um aumento do esforço para alcançar o objetivo na jogada e a vitória na competição. O quanto que essa percepção do atleta sobre sua performance no lance inicial, e seu estado mental positivo, decorrente dessa percepção, irá se traduzir em uma melhora no desempenho esportivo depende do quanto a sua atenção e seu nível de excitação fisiológica se alteraram de maneira consistente, de acordo com a demanda da tarefa que ele objetiva realizar (Taylor \& Demick, 1994).

Nesse modelo é ressaltada a importância dos fatores do oponente, isto é, o momento psicológico do adversário (Taylor \& Demick, 1994). Por exemplo, se um centroavante dribla um oponente, esse atacante vivencia um momento positivo, ou seja, em função de ter acertado um lance, cumprido seu objetivo, levando vantagem sobre o adversário, há uma mudança positiva na sua cognição, no afeto e no sistema fisiológico. Dessa forma, ele se sente mais confiante, aumenta sua auto-estima e seus músculos se enrijecem com maior intensidade. Essa mudança positiva influencia seu comportamento; ou seja, o jogador corre mais rápido e realiza a jogada com mais vigor e, conseqüentemente,

\footnotetext{
1 Traduções literais dos nomes dos modelos originalmente em inglês.
} 
melhora a sua performance. Apesar disso, de acordo com o Modelo Multidimensional, essa melhora na performance somente resultará em uma mudança no resultado da jogada se o adversário estiver vivenciando um momento psicológico negativo. Razão pela qual em um jogo, quando um jogador dribla um adversário em direção a goleira, essa ação só resultará em uma vantagem significativa, se esse oponente estiver em um momento negativo, sentindo-se derrotado.

Em um outro modelo que analisa a relação do momento psicológico com a performance, chamado Modelo Antecedentes-consequências (AntecedentsConsequences Model, Vallerand \& Colavecchio, 1998) afirma que MP refere-se à percepção do jogador, no que concerne a sua performance, quando progride em seu objetivo numa jogada, tendo como resultado desse sucesso no início do lance um aumento da motivação, da percepção de controle, do otimismo, da energia e do sincronismo de suas ações. Se o atleta não é bem sucedido na jogada inicial, há uma redução desses mesmos aspectos (Vallerand \& Colavecchio, 1998).

O Modelo Antecedentes-conseqüências postula que variáveis situacionais que antecedem uma jogada podem afetar o MP. Precisamente, circunstâncias que antecedem uma jogada ou mesmo a maneira como uma jogada começa, como, por exemplo, com uma grande roubada de bola, podem melhorar o momento psicológico. Vivenciar uma melhora na percepção do MP, isto é, experenciar um momento positivo, no qual o atleta esteja se sentindo motivado, otimista, com bastante energia, tendo controle e sincronismo em suas ações, pode resultar numa melhora na performance. Da mesma forma, uma diminuição na motivação, no otimismo, na energia, etc., resultando num momento negativo, pode ser extremamente prejudicial ao desempenho do jogador no lance.

Esses modelos servem como ferramentas para que se possa avaliar o que acontece com os atletas em termos cognitivos, afetivos, fisiológicos e comportamentais, nos segundos que duram um lance ou uma jogada no decorrer de uma partida. Possibilitam assim o debate acadêmico do que antes era analisado com uma abordagem exclusivamente intuitiva, dando um caráter científico aos fenômenos inerentes a uma competição esportiva.

Entretanto, possivelmente esses não sejam modelos completos, definitivos e exclusivos, embora o momento psicológico muito provavelmente influencie a performance, mas num cenário complexo como do esporte de competição hoje em dia, acreditar que apenas o momento psicológico determina a performance é decisivamente uma premissa falsa.
Segundo Vallerand e Colavecchio (1988), a influência do MP sobre a performance depende de variáveis situacionais e pessoais como nível de ansiedade e de motivação, assim como da própria natureza da tarefa que está sendo executada. Dessa forma, o grau de facilidade e de dificuldade de uma ação esportiva também influencia a performance.

A validade dos modelos que relacionam o momento psicológico e a performance foi verificada por uma pesquisa de Perreault e Vallerand (1998) com 20 ciclistas. O resultado desse trabalho sugere que os modelo de Taylor e Demick (1994) e de Vallerand e Colavecchio (1988) explicam a relação momento psicológicoperformance. Esse estudo demonstra, experimentalmente, que a vivência de um momento psicológico positivo pode facilitar a performance em tarefas que exijam um grande esforço.

Existem vários fatores que podem favorecer a percepção de um momento psicológico positivo. A coesão do time e a vantagem no escore da partida são alguns desses fatores (Eisler \& Spink, 1998). Membros de times mais coesos e unidos em prol do objetivo comum de ganhar o jogo avaliam sua equipe como tendo um MP mais positivo que aqueles que não são tão coesos. A configuração de um escore positivo na partida, ou seja, o fato do time estar ganhando cria um clima favorável à percepção e à vivência de um MP superior ao do time adversário.

O grande valor de se investigar esses modelos é justamente definir seu campo de validade, isto é, analisar em que circunstâncias o MP pode ser um elemento mais decisivo. Além do momento psicológico, o nível de ansiedade também parece estar relacionado com o desempenho esportivo.

\section{Ativação, Ansiedade e a Performance}

Os termos ativação, ansiedade e estresse possuem semelhanças e interfaces importantes e são consideradas de fundamental importância para o desempenho do atleta. Para a Psicologia do Esporte é preciso defini-los claramente como fenômenos.

A ativação envolve atividades fisiológicas e psicológicas e refere-se às dimensões de intensidade de motivação em um determinado momento. Pode variar de um estado de letargia a uma intensa euforia ou agitação. A ativação não está necessariamente associada a eventos agradáveis ou desagradáveis. Um atleta pode ficar altamente ativado ao vencer um campeonato e reagir da mesma forma a uma derrota em uma competição importante (Weinberg \& Gould, 2001). 
A ansiedade é um fenômeno psicológico relacionado à adaptação e regulação do ser humano na vida cotidiana. Trata-se de uma reação subjetiva de apreensão e incerteza acompanhada por uma ativação do sistema nervoso autônomo e um aumento da atividade endócrina (Brandão, 1995). Essa reação de apreensão e incerteza, que gera reações fisiológicas como taquicardia, dor de estômago, medo, entre outras, é denominada Ansiedade-Estado. Weinberg e Gould (2001) complementam essa definição, afirmando que esse estado ansioso está relacionado ao componente de humor em constante variação, caracterizado por sentimentos de apreensão e tensão, associados à estimulação do Sistema Nervoso Autônomo. A Ansiedade-Estado é representada em seu aspecto cognitivo quando a pessoa se preocupa ou tem pensamentos negativos e, somática, quando existem alterações na percepção subjetiva da ativação fisiológica (Weinberg \& Gould, 2001).

Ansiedade-Estado está diretamente relacionada à Ansiedade-Traço, ou seja, uma predisposição para perceber as situações em geral como ameaçadoras (Brandão, 1995). Para Spielberg (1996) essa Ansiedade-Traço faz parte da personalidade e trata-se de uma tendência ou disposição comportamental adquirida que influencia o comportamento. Nesse caso, a pessoa responde a circunstâncias percebidas como ameaçadoras com reações ou níveis de estado de ansiedade exacerbados em intensidade e magnitude em relação ao perigo real e objetivo.

Atletas com alto índice de Ansiedade-Traço tendem a apresentar elevado nível de Ansiedade-Estado. Um índice alto ou baixo de Ansiedade-Estado é muito pouco elucidativo para explicar a performance. Essa depende de características pessoais do atleta, ou seja, do modo como ele lida com sua ansiedade e com seu estado de ativação (Brandão, 1995). Hanin $(1980,1986,1997)$ traz uma contribuição importante à Psicologia do Esporte ao apresentar o seu modelo de zonas individualizadas de desempenho ideal (IZOF - Individualized Zones of Optimal Functioning). Ele verificou que atletas de elite têm uma zona de ansiedade-estado ideal na qual ocorrem seus melhores desempenhos. O nível ideal de ansiedade-estado é subjetivo, variando de acordo com as características dos atletas. Pode ser baixo, para alguns esportistas que precisam estar com o nível de ansiedade bem baixa, bem calmos para atingir bons desempenhos; médio para atletas que necessitam estar com a ansiedade sobre controle, mas também com o Sistema Nervoso um tanto quanto ativado; ou alto para os que obtêm as melhores atuações quando estão bastante agitados. Quando um atleta está com um nível de ansiedade ótimo, ele está psicologicamente em controle. Ao contrário, quando seu índice de ansiedade está fora de controle, mais baixo ou mais alto que seu nível ótimo, aparecem reações cognitivas como medo, pensamentos negativos e desinteresse representado no nível somático por tensões musculares, lentidão e pouca explosão (Brandão, 1995).

Hardy $(1990,1996)$ complementa esse modelo afirmando que para o desempenho ideal não é suficiente um nível de ativação fisiológica ideal: é necessário também controlar a ansiedade-estado cognitiva (preocupação), pois que mesmo atletas que necessitam de um nível de ansiedade-estado cognitiva alto, os aumentos na ativação podem atingir um limiar imediatamente subseqüente à ativação ideal, onde os níveis de ativação fisiológica são tão intensos que ocorre em seguida um rápido declínio no desempenho.

Gould e Weinberg (2001) apontam que para a interpretação de um indivíduo de seus sintomas de ansiedade é importante a compreensão da relação ansiedadedesempenho. As pessoas podem considerar os sintomas de ansiedade como facilitadores, positivos e úteis para o desempenho ou, por outro lado como negativos e prejudiciais. Assim sendo o autor demonstra que para entender a relação ansiedade-desempenho é preciso examinar tanto a intensidade quanto a direção (da interpretação da ansiedade como facilitadora ou debilitante) da ansiedade apresentada.

Pesquisas demonstram que ativação e ansiedade aumentada causam aumento da tensão muscular e podem interferir na coordenação, além disso, estreitam o campo de visão, tornando o foco diminuído, o que pode ser favorável para exercícios que exijam concentração num foco estreito e a eliminação de distrações ambientais (Nideffer, 1976; Weinberg \& Gould, 2001).

\section{Estresse e Esporte}

O estresse acontece quando há um desequilíbrio substancial entre as demandas físicas e psicológicas impostas a um ser humano, sob condições em que a falha em satisfazê-las tem conseqüências importantes, e sua capacidade em responder satisfatoriamente (Weinberg \& Gould, 2001).

Muitos são os fatores oriundos do meio externo que levam ao estresse no esporte como, por exemplo, estímulos de dor, perturbações sensoriais (muitos estímulos como barulho, luz ou vibração), ou situações de perigo (acidentes, lesões). Há também o estresse gerado por situações de privação das necessidades básicas, como sono e alimentação. Os estressores de performance, como demanda excessiva ou diminuída de jogos, insatisfação no trabalho (clube) e o fracasso em situações de performance, e os estressores 
sociais como conflitos com o técnico ou membros da equipe, viagens muito longas, distância dos parentes e isolamento social são outros fatores que prejudicam a performance esportiva. Outros fatores como a pressão da torcida, a imprensa e a relação com patrocinadores também podem prejudicar o desempenho dos atletas (Brandão, 1995).

\section{A Satisfação do Atleta no Trabalho}

Muitos aspectos estão associados à satisfação dos atletas em seu trabalho. A performance individual e coletiva, a liderança, a coesão da equipe, os aspectos organizacionais e administrativos do clube são alguns desses fatores que podem aumentar o grau de satisfação dos jogadores (Riemer \& Chelladurai, 1998). Na maior parte das vezes, vencer é o objetivo principal dos esportistas, razão pela qual a performance individual assume um papel tão importante no que se refere à satisfação dos atletas no trabalho.

Outro aspecto importante que Riemer e Chelladurai (1998) apontam se refere às questões de liderança, principalmente no que concerne ao papel do técnico e à influência de suas ações no grupo de jogadores. Essas ações estão relacionadas à mobilização, ao desenvolvimento e à utilização dos recursos humanos disponíveis. Dessa forma os atletas reagem positiva ou negativamente à forma como o técnico utiliza a habilidade técnica e tática dos jogadores, seleciona e aplica estratégias de comando apropriadas, treina e instrui os atletas e trabalha individualmente com cada jogador.

A estruturação do time, ou seja, a maneira como os integrantes trabalham juntos, a integração do grupo, as contribuições individuais e coletivas para as tarefas são outros fatores importantes para a satisfação dos atletas no trabalho. No contexto das competições esportivas, o time e os membros de uma equipe podem facilitar a performance individual e propiciar um suporte social significativo aos demais. O suporte organizacional, isto é, a assistência do departamento de futebol profissional dos clubes é importante para o time e para seus membros. Apesar do técnico, da equipe e do departamento de futebol estarem próximos aos atletas, os jogadores também desenvolvem um senso de satisfação na relação com agentes externos como a mídia, a comunidade e os fãs (Riemer \& Chelladurai, 1998).

\section{As Grandes Competições e a Performance}

O contexto das grandes competições esportivas, como as Olimpíadas e os campeonatos de âmbito mundial e nacional, exerce importante influência nos atletas. Muitas equipes se motivam e têm um rendimento acima do esperado nos grandes torneios. Outras, entretanto, falham e seu desempenho fica aquém de sua capacidade. De acordo com algumas pesquisas relevantes (Gould, Guinan, Greenleaf, Medbery \& Peterson, 1999; Jackson, Mayochi \& Dover, 1997; Willians \& Krane, 1998; Woodman \& Hardy, 1998), os fatores abaixo relacionados estão associados a uma boa performance nessas competições:

\section{Programa de Treinamento da Equipe}

Um programa de treinamento voltado para uma competição importante favorece a obtenção de bons resultados. Nesses programas, os atletas convivem um bom período de tempo treinando juntos antes das competições, em um local afastado de possíveis distrações, focalizando a atenção no trabalho. Dessa forma, a comissão técnica do clube pode controlar o ambiente de treinamento, tomando as precauções para o bom andamento das atividades (Gould \& cols., 1999). Desde essa perspectiva, os autores ressaltam a importância da inclusão de treinamentos de alto e baixo impacto alternados e de estratégias de manejo do estresse e da ansiedade dos atletas. Segundo Willians e Krane (1998), rotinas bem desenvolvidas e planejadas, antes e durante a competição, favorecem uma boa performance dos atletas. No Brasil, os clubes realizam pré-temporadas visando o aperfeiçoamento físico, técnico e tático da equipe para toda a temporada e raramente realizam um trabalho específico para uma competição. Isso pode ser atribuído às dificuldades do calendário dos jogos, onde os clubes disputam muitos torneios ao mesmo tempo, dificultando o planejamento de um programa de treinamento voltado para o sucesso em um determinado torneio.

\section{Preparação Mental}

Em todas as grandes competições esportivas, os atletas são submetidos a situações de muita pressão e estresse. Segundo Hardy e Woodman (1998), problemas na organização dos torneios podem atrapalhar a performance dos jogadores. Os times que obtêm sucesso, entretanto, mencionam que a realização de um trabalho de preparação mental os torna aptos para lidar com tais situações (Gould \& cols., 1999). Esse trabalho inclui o uso de técnicas de imaginação e de visualização de eventos que podem distraí-los (Willians \& Krane, 1998). Dessa forma, no momento da competição, os jogadores já sabem o que fazer para que esses tipos de situações não atrapalhem sua atuação.

\section{Apoio da Torcida}

Os times que obtêm sucesso mencionam o grande número de torcedores nos estádios como uma influência 
positiva em sua performance. Os jogadores se motivam com a vibração da torcida com suas jogadas e valorizam a oportunidade de mostrar aos torcedores suas habilidades (Gould \& cols,, 1999).

\section{Apoio da Família e dos Amigos}

Membros de times vencedores percebem que os amigos e familiares auxiliam, amparam e encorajam os atletas, fornecendo uma estrutura de apoio para que os atletas possam manter o foco de sua atenção na competição. Além disso, as equipes de sucesso ensinam à família como lidar com as demandas dos esportes de alto rendimento. Muitas vezes as comissões técnicas explicam aos familiares como eles podem se tornar um grande auxílio aos atletas (Gould \& cols., 1999).

Jackson e colaboradores (1997) também atentam para a importância do que chamam de suporte social, ou seja, as pessoas com quem os jogadores podem contar para auxiliálos na preparação e no decorrer da competição. Desde essa perspectiva, os amigos, o técnico, os outros jogadores do time e os familiares fazem parte do suporte informal, enquanto o psicólogo esportivo e os administradores dos clubes compõem o suporte formal aos atletas.

\section{Concentração, Empenho, Motivação e Autoconfiança}

Times que têm maior capacidade de manter um alto nível de concentração, motivação e empenho tendem a ter uma boa performance. Os jogadores dessas equipes são autoconfiantes, direcionam sua energia à conquista de seu objetivo na competição e se esforçam ao máximo para conseguir o melhor desempenho possível (Gould \& cols., 1999).

\section{União do Grupo de Jogadores}

A coesão do time é um fator importante para uma boa performance. $\mathrm{O}$ respeito entre os jogadores facilita a união do grupo e, nesse sentido, a presença de um líder, de um capitão, é um componente importante para auxiliar nessa integração. Assim sendo, nas equipes coesas, os atletas se incentivam para que cada um faça o máximo possível para auxiliar o time em campo (Gould \& cols., 1999).

\section{Biomecânica Aplicada ao Futebol}

A biomecânica é a ciência que estuda as forças que atuam sobre os corpos vivos. Quando um jogador cabeceia ou chuta a bola, há um impacto sobre os pés e a cabeça do atleta. Nas situações em que o esportista

Tabela 1

Sumário da Literatura Existente Sobre Performance de Alto Rendimento

Autores Fatores associados a uma boa performance

Gould e colaboradores (1999)

Programa de treinamento semelhante a pré-temporada antes das competições

Apoio da torcida (gostar de jogar com público assistindo)

Suporte de amigos e família

Preparação mental

Motivação, empenho, confiança e autoconfiança

União do grupo de jogadores

Planejamento adequado das rotinas nas competições

Altos níveis de motivação e comprometimento

Habilidade para lidar com distrações e com eventos inesperados

Krane e Willians (1998)

Altos níveis de autoconfiança

Manter altos níveis de concentração

Eisler e Spink (1998)

Orlick e Partington (1998)

Momento Psicológico no decorrer da partida

Habilidade de atenção concentrada, de manter o foco de atenção

Habilidade de controlar a imagem que o atleta tem de sua própria performance

Comprometimento total em alcançar excelência na performance

Treinamento de alta qualidade

Riemer e Chelladurai (1998) Performance individual e coletiva

Liderança, sobretudo do treinador

Coesão da equipe

Aspectos organizacionais e administrativos

Brandão (1990)

Conseguir manter um nível de ansiedade ótima 
salta, suas pernas se chocam com o chão na descida. Esses são alguns exemplos que demostram a constante influência de diferentes forças envolvidas nas ações dos jogadores em campo.

Existem fatores biomecânicos que possuem significativa importância para o sucesso no futebol. A técnica e a habilidade dos jogadores podem ser influenciadas pelo equipamento usado nos jogos. Essa interação entre atleta e equipamento tem efeitos na performance e na proteção contra lesões (Less \& Nolam, 1998).

A qualidade da bola, das chuteiras, das caneleiras e da superfície do gramado influenciam diretamente a eficácia dos movimentos dos atletas na partida. Assim sendo, na medida em que esses fatores, com os quais o jogador interage, forem precisamente elaborados, o chute, o cabeceio, o passe ou o drible tendem a ter maiores possibilidades de serem certeiros (Less \& Nolam, 1998).

Existem muitas técnicas de modelação biomecânica que ajudam a entender os mecanismos subjacentes à performance. Apesar disso, elas têm sido pouco utilizadas (Less \& Nolan, 1998). No Brasil, particularmente, muitos gramados têm condições precárias, dificultando assim o desempenho dos atletas. As chuteiras e as bolas são projetadas sem levar em conta os modelos biomecânicos que auxiliariam na interação desses equipamentos com os jogadores. Como conseqüência disso, os atletas podem se machucar pela pouca capacidade de proteção que alguns equipamentos lhes oferecem. $\mathrm{O}$ choque da bola com a cabeça dos atletas pode causar, inclusive, prejuízo neurológico (Matser, 1999). Assim sendo, evidencia-se a importância de propiciar aos jogadores o uso de equipamentos projetados de acordo com os modelos biomecânicos, pois com isso, pode-se evitar lesões e melhorar a performance.

\section{Método}

Esse estudo trata de uma investigação que teve como objetivo analisar as principais características contextuais relacionadas à performance do jogador de futebol e compreender, na visão de profissionais consagrados nesse esporte, os fatores que influenciam a performance dos jogadores. Além disso, está sendo construído um questionário sobre os fatores relacionados à performance dos jogadores de futebol profissional. Através da visão geral de ex-jogadores, preparadores físicos, de treinadores e dos próprios jogadores de futebol, realizou-se uma investigação dos aspectos considerados relevantes para a performance nos jogos, bem como dos fatores que facilitam e dificultam a performance dos atletas.
Foi utilizada uma metodologia qualitativa. Optou-se por esse procedimento, pois a presente fase da pesquisa é realizada de forma ampla, orientada para os processos psicossociais e a descoberta de questões importantes acerca das vivências do jogador de futebol. Houve preocupação de entender o que está ocorrendo no contexto que envolve os atletas. Buscou-se explorar ao máximo os conteúdos trazidos pelos participantes a fim de que esse trabalho possibilite uma ampla compreensão acerca dos fatores relacionados à performance dos atletas.

\section{Participantes}

Os participantes foram 2 ex-jogadores, 2 preparadores físicos, 2 treinadores e 2 jogadores de futebol que ainda atuam, sendo todos residentes na cidade de Porto Alegre e de nível sócio-econômico de médio a alto, selecionados a partir do critério de conveniência. Todos os sujeitos possuem vasta experiência na carreira (mais de 10 anos) e muitos títulos conquistados (mais de 3 cada um na carreira).

\section{Procedimentos}

Foram feitas entrevistas individuais semi-estruturadas com todos os profissionais investigados. A partir da autorização por parte da direção dos clubes, estabeleceramse contatos telefônicos para marcar o horário e o local das entrevistas. Os dados foram coletados em salas das concentrações dos estádios com a utilização de gravador para registro dos dados, com o consentimento dos entrevistados. Foram investigados os seguintes aspectos: dados biodemográficos, incluindo idade e escolaridade, tempo de profissão e títulos conquistados; fatores relacionados à performance dos atletas nos jogos; fatores que facilitam a performance dos atletas nos jogos e fatores que dificultam a performance dos atletas nos jogos.

\section{Procedimentos para Análise dos Dados}

Para definição das categorias analíticas utilizou-se a análise de conteúdo de acordo com o modelo misto (Laville \& Dione, 1999), pois esse modelo permite que categorias sejam selecionadas inicialmente a partir do ponto de vista teórico, mas também que sejam modificadas a partir do que a análise aporta. Realizou-se uma análise de conteúdo sobre os dados das entrevistas, através da seguinte seqüência de passos: a) transcrição das entrevistas e preparo das informações, com elaboração de categorias prévias a partir da revisão de literatura; b) leitura do material obtido com o intuito de obter uma compreensão geral dos dados; c) recorte dos conteúdos em elementos que pudessem ser agrupados em categorias, com o intuito de se levantar pontos que assim 
recortados constituíssem as unidades de análise e de classificação; d) identificação de unidades de análise, tendo como foco o fenômeno pesquisado; e) classificação das unidades em categorias; f) validação das categorias pelo método dos juizes e, enfim g) Descrição das categorias.

Uma vez transcritas as fitas gravadas, foram organizadas algumas categorias centrais que se repetiam no discurso dos jogadores entrevistados. Depois de repetidas leituras analíticas dos discursos, foram sendo desveladas as percepções dos sujeitos sobre os fatores que influenciam a performance e sobre o contexto que envolve o jogador de futebol. Além disso, utilizou-se o método dos juizes para confirmar o levantamento das categorias analíticas criadas pelos pesquisadores. Esse método consiste em apresentar os itens levantados a experts no assunto e pedir que categorizem da forma que considerarem mais pertinente. Os experts que realizaram esse procedimento são ex-jogadores de futebol que também foram treinadores e conquistaram muitos títulos exercendo atualmente a profissão de cronistas esportivos.

\section{Resultados}

As entrevistas individuais e a categorização realizada pelos experts demonstraram não somente os aspectos positivos e negativos influenciando a performance dos atletas, mas a importância de se perceber a interação dos fatores que compõem o cenário da performance. Os resultados mostram os fatores contextuais, psicológicos e técnicos, físicos e táticos considerados importantes pelos entrevistados para a performance dos jogadores. Acima de tudo, fica evidenciado que não há um único fator ou uma "fórmula mágica" que determina um grande desempenho. Existem sim muitos fatores que contribuem para a performance de alto nível.

\section{Categorias Levantadas nas Entrevistas e Validadas pelos Experts}

\section{Fatores Psicológicos}

\section{Motivação, Confiança e Preparação Psicológica}

Foram citados fatores que dizem respeito à influência da confiança, da motivação e da preparação psicológica na performance. Equilíbrio, autocontrole, saber se proteger foram outros fatores citados como importantes nessa categoria. Os atletas ressaltam a importância de manter o controle no futebol, que é um esporte de muita competitividade, combatividade e envolve muitas pressões. A importância de se ter uma postura regrada e voltada aos objetivos ficaram evidentes em declarações como: "Tem que saber se cuidar", "Lutar pelos objetivos", "É importante fazer e enxergar coisas corretas", "Temos que executar ações objetivas voltadas para o resultado" e "O jogador tem que saber onde quer chegar, ter metas claras e objetivas". A confiança como fator que conduz o atleta ao sucesso fica evidente nas seguintes afirmações: "É importante confiar em si, não ter medo do sucesso, não ter medo de ser feliz". "O jogador precisa aprender que tem uma grande força interna e dar o melhor de si, pois assim alcançará seus objetivos".

Outro fator citado no discurso dos sujeitos é a importância de sentir e de vivenciar as vitórias e derrotas. Isso é relatado como um fator de maturidade, ao passo que possibilita aprender com os erros e vibrar e se entusiasmar com os acertos, aumentando a confiança para novas conquistas.

\section{Momento Psicológico no Decorrer das Partidas}

Nessa categoria apareceram os fatores relacionados à influência de diferentes situações dos jogos na performance. Conseguir controlar as emoções, sabendo lidar com a alternância no placar e conseguindo também

Tabela 2

Categorias Levantadas nas Entrevistas e Validadas pelos Experts

Aspectos

Aspectos psicológicos

Suporte social

Aspectos técnicos, táticos e físicos

\section{Categorias}

Motivação, confiança e preparação mental

Momento psicológico no decorrer da partida

Contexto e formação profissional

Contexto e formação social e familiar

Grupo

Papel do treinador

Aspectos físicos 


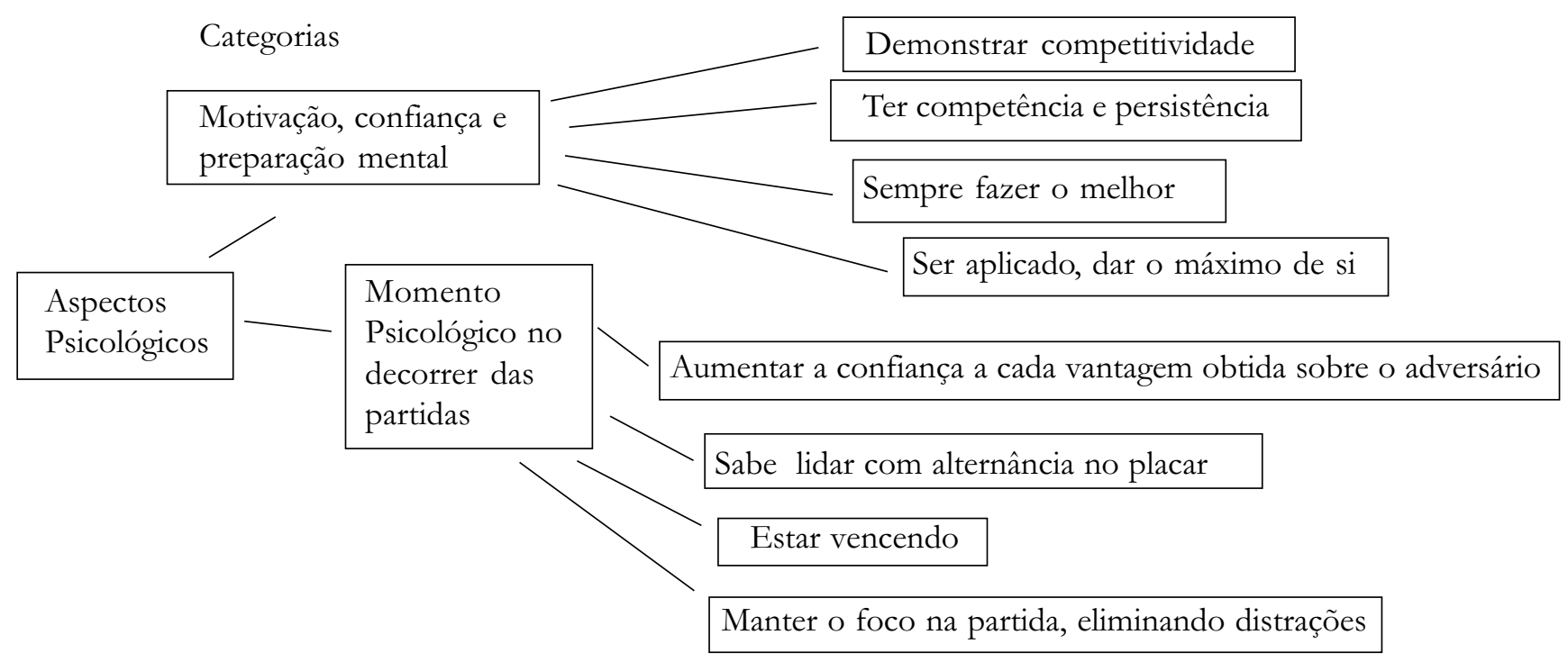

Figura 1. Aspectos psicológicos.

dar uma boa resposta nas diferentes situações pelas quais o atleta passa durante a partida foram questões citadas como importantes para uma boa performance. Além disso, aumentar a confiança a cada vantagem obtida sobre o adversário e estar vencendo o jogo também foram alguns dos fatores mais citados.

Os entrevistados relataram que um time que está vencendo aumenta seus níveis de confiança, de vibração, atua com mais "garra" e consegue superar seus limites nos jogos. Foi citada também a importância do autocontrole para conseguir lidar com a pressão por resultado no decorrer da partida. "É importante estar vencendo, pois assim aumenta a confiança e a vibração. Vitória consolida trabalho" e "É preciso manter o controle estando perdendo ou ganhando" são exemplos de relatos que ilustram bem esses aspectos.

Pela Figura 1 é possível a visualização das categorias que dizem respeito aos aspectos psicológicos citados pelos entrevistados.

\section{Suporte Social}

\section{Contexto e formação profissional}

Questões básicas referentes à retaguarda oferecida pelo clube e ao contexto cotidiano das relações profissionais apareceram com freqüência nos relatos dos atletas. Relataram que o clube tem que dar tranqüilidade para o atleta jogar, orientar com competência e contar com uma boa estrutura de apoio. A importância de se ter um bom convívio com a imprensa e a torcida também foi ressaltada nesse item. Uma estrutura administrativa bem definida também foi citada como importante para o rendimento.
Fatores relacionados à trajetória profissional dos atletas e sua influência no desempenho esportivo como a preparação desde as categorias de base, o aprimoramento de fundamentos técnicos e as experiências obtidas são alguns dos principais aspectos levantados nessa categoria. “... É preciso aprender com a experiência, ir ganhando confiança e ter tido bons treinadores nas categorias de base..." são exemplos colhidos do discurso dos atletas que ilustram bem esse fenômeno. Além disso, os atletas ressaltaram a importância das repetições de situações e de jogadas vivenciadas tanto nos treinamentos quanto nos jogos como um fator importante para uma boa performance.

Todos os entrevistados consideram a importância de se ter prazer em jogar futebol como algo que influencia positivamente a performance, aumentando a motivação e a confiança. Nesse sentido, verifica-se que há um bem-estar proveniente do fato de se gostar do que se faz explicitado por manifestações como: “(...) é importante gostar de jogar futebol, ter prazer na tua atividade profissional faz com que tu fique bem consigo mesmo (...)".

\section{Contexto e formação social e familiar}

Fatores que dizem respeito à família e às relações sociais dos atletas são vistos como um suporte que lhes possibilita "(...) ter uma forte estrutura para lidar com pressão (...)". Uma "sólida estrutura familiar" e “(...) não ter medo do sucesso (...)" apareceram, no discurso dos entrevistados, como aspectos importantes que envolvem o contexto e a formação social e familiar. Eles percebem a importância dos familiares como algo fundamental, ressaltando a importância da relação com os pais e o carinho recebido desses em ações como, por exemplo, 
levar os atletas, principalmente nas categorias de base, aos jogos. Segundo os atletas, isso lhes permite “(...) estar bem consigo mesmo e tranqüilo para jogar (...)”.

Saber diferenciar críticas construtivas das destrutivas, ter bons valores, boa índole e bons exemplos em casa foram outros fatores bastante citados. Da mesma forma, fazer e enxergar coisas corretas, ter tido pai ou familiar que já foi jogador de futebol e a importância de se transpor princípios de vida para a atividade profissional também apareceram com freqüência. Os atletas relatam “(...) é importante ter valores como companheirismo, amizade, respeito, disciplina e educação (...)”.

\section{Grupo}

Aspectos ligados aos relacionamentos grupais, como a união, o respeito, o companheirismo e a amizade foram valores ressaltados no depoimento dos sujeitos. "É fundamental todos estarem unidos, se respeitarem e terem companheirismo e amizade..." é um exemplo de um relato que ilustra bem esses aspectos.

Fica claro também nas entrevistas realizadas que é importante que todos partilhem das decisões e que não haja disputas por vaidades. Os participantes ressaltam ainda que “(...) devemos saber que a alegria de um é a alegria de todos, assim como o problema de um é o problema de todos (...)".

A doação dos atletas ao grupo e a força da equipe de jogadores, tendo pelo menos 24 atletas (dois para cada posição) se respeitando e sabendo que todos possuem qualidades, foram outros aspectos citados como fundamentais para uma boa performance. Além disso, os atletas ressaltaram a importância de no grupo existirem jogadores experientes e jovens para o rendimento do time. Nesse sentido, os sujeitos afirmam que "(...) todos devem se doar ao time (...)" e que “(...) é fundamental para uma boa performance estar num grupo forte com bons jogadores (...)".

Os aspectos que dizem respeito ao suporte social recebido pelos atletas podem ser visualizados na Figura 2.

\section{Aspectos Técnicos, Táticos e Físicos Papel do treinador}

Nessa categoria foram levantados aspectos relacionados às ações que a comissão técnica deve executar a fim de propiciar condições favoráveis a uma boa performance dos atletas. Nesse sentido, apareceram fatores que vão desde a organização tática da equipe, passando pela preparação emocional e pela administração do grupo, chegando aos métodos de trabalho propriamente ditos. Nesse sentido, os atletas citaram a importância de se ter uma comissão técnica bem preparada, experiente e que realiza cursos, inclusive de Ensino Superior.

Os sujeitos comentaram sobre a importância do treinador fazer os atletas assimilarem seus métodos de trabalho, aprimorarem fundamentos técnicos e táticos e manterem a disciplina. Harmonizar setores da equipe,

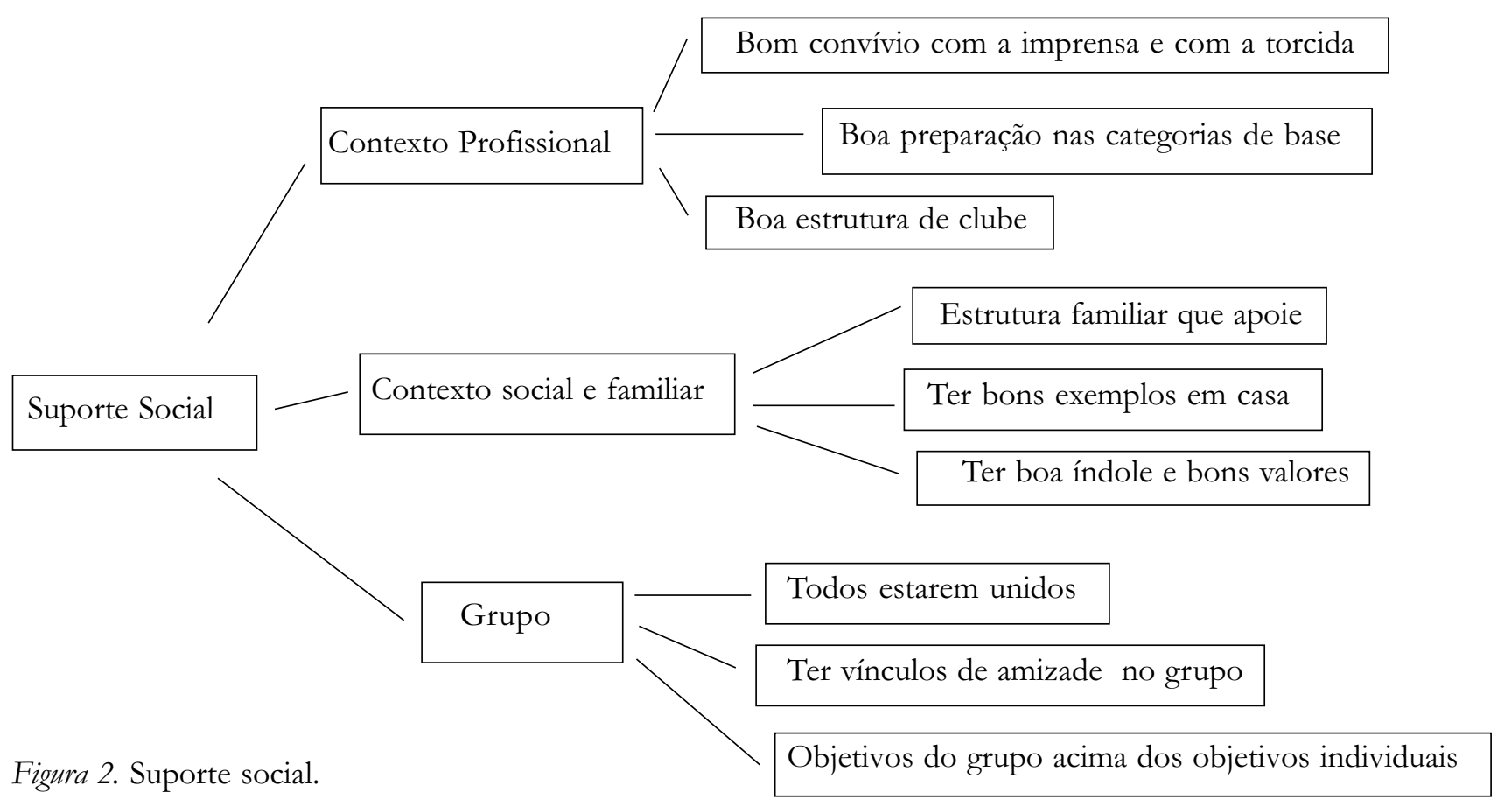

Psicologia: Reflexão e Crítica, 2002, 15(2), pp. 447-460 
organizar taticamente o time e treinar a todos de forma igual (tanto titulares quanto reservas) foram outros fatores citados como funções cruciais do treinador.

No que concerne à relação com o grupo de jogadores foram ressaltados aspectos como ser empático e correto, ter uma boa identificação com os atletas e estar próximo no acerto e no erro. A importância de o treinador conquistar a simpatia do grupo e de dar atenção a todos também foi muito citada, os participantes comentaram “... é muito bom trabalhar com um técnico que seja claro e verdadeiro, que esteja junto dos atletas não só no acerto, mas também no erro e que dê atenção a todos...".

Os entrevistados referiram também que o treinador deve saber "... puxar as coisas para frente, estabelecer objetivos e metas...”. Ressaltaram ser fundamental que a comissão técnica trabalhe com ações claras, estabelecendo alvos próximos, “...buscando alcançá-los por etapas e passando confiança...". Além disso, o treinador e sua comissão devem saber dosar o trabalho, tendo qualidade ao invés de quantidade de trabalho, proporcionando condições para desenvolver o potencial dos atletas juntamente com um bom planejamento das competições.

\section{Aspectos Físicos}

Nesse item apareceram desde aspectos relacionados à constituição, preparação física e até a própria alimentação dos jogadores. A importância dada à capacidade física centrada na força, velocidade, resistência física e explosão muscular foi bastante ressaltada.

Possuir uma "valência nata física", termo utilizado pelos treinadores que significa ter um biotipo adequado às exigências de uma partida de futebol, também foi um aspecto bastante trazido. A fala "Hoje em dia velocidade é fundamental, o jogador tem que estar bem preparado fisicamente para que possa utilizar suas qualidades físicas fundamentais como estatura, força, capacidade de explosão muscular e resistência física" ilustra bem os aspectos levantados nessa categoria.

As questões referentes à categoria que envolve os aspectos técnicos, táticos e físicos podem ser bem observadas na Figura 3.

\section{Discussão}

Os resultados desse estudo estão em consonância com uma série de trabalhos anteriores relacionados ao tema da performance no esporte. Como colocam Williams e Krane (1998), fatores tais como altos níveis de motivação, estratégias para manter o foco de atenção na partida e eliminar distrações e o estabelecimento de planos de trabalho claros e objetivos estão diretamente relacionados a uma boa performance e ao sucesso nas competições.

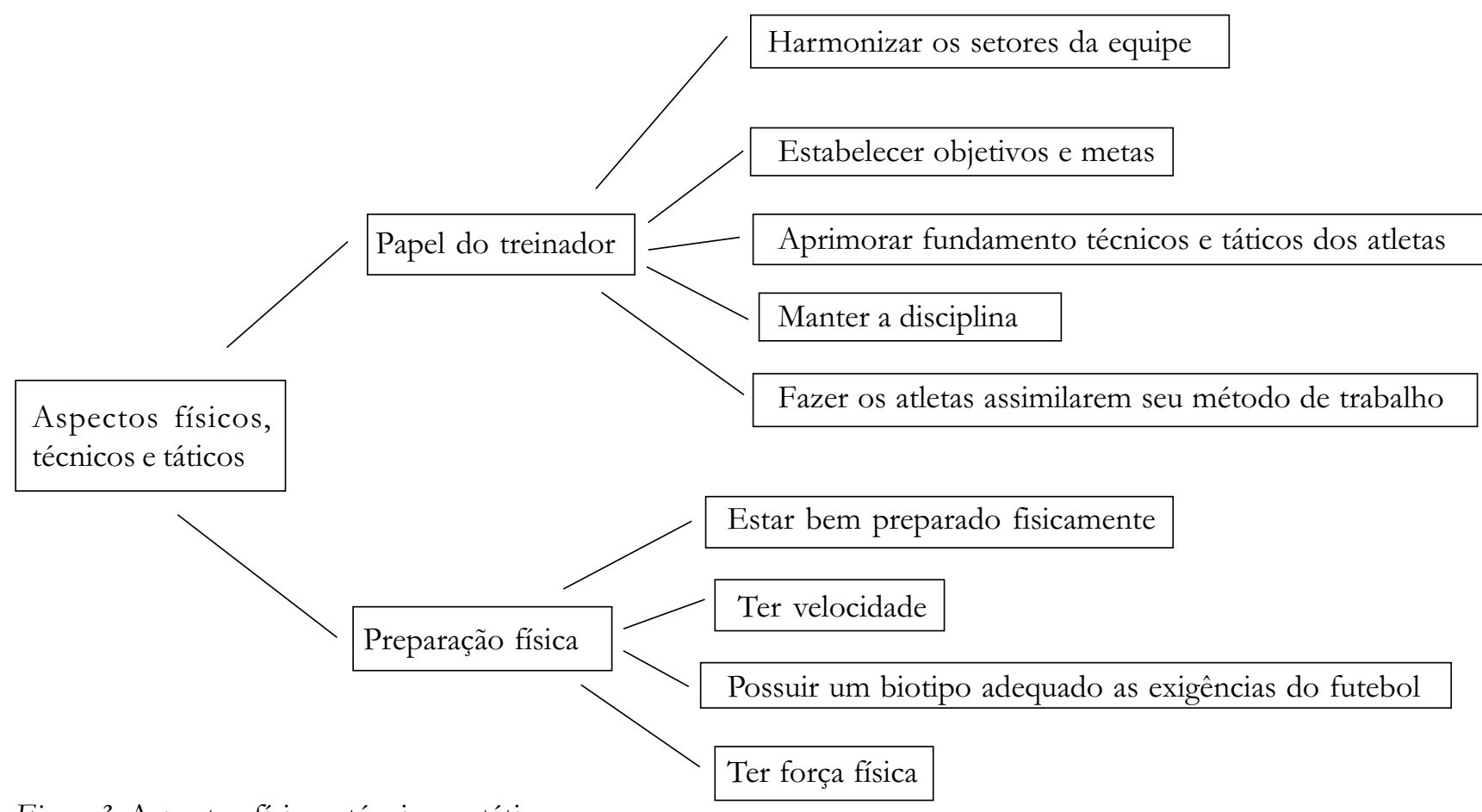

Figura 3. Aspectos físicos, técnicos e táticos. 
Orlick e Partington (1998), em seus estudos, também salientam a importância de se manter a concentração, a capacidade de se autocontrolar, o comprometimento para alcançar excelência na performance e do treinamento adequado às necessidades individuais dos atletas. Os achados desse estudo demonstram a importância desses fatores. Mostram também que, quando os atletas falam em manter a concentração, eles estão ressaltando a importância de se manter o foco de atenção na partida, eliminando distrações, preocupando-se unicamente com o jogo e mantendo o equilíbrio.

Parece que o que possibilita a satisfação do atleta no trabalho e a tranqüilidade para que ele se preocupe unicamente com o jogo é o suporte social oferecido pelo clube, pela família e pelo próprio grupo de jogadores. Jackson e colaboradores (1997), ressaltam a importância desse suporte subdividindo-o em suporte formal e suporte informal. Os autores apontam o técnico, a família, os amigos, a esposa, o time e os mentores ou ídolos no esporte como sendo o suporte informal. Por outro lado, denominam de suporte formal a figura do psicólogo do esporte, do manager, da instituição onde o atleta trabalha e do programa de trabalho.

Os resultados desta pesquisa apontam para a necessidade de renomear essas categorias uma vez que os participantes ressaltaram a influência em sua performance, não só do suporte atual que recebem, mas também e, fundamentalmente, da importância da família em sua criação, dos treinadores das categorias de base, que muito lhe ensinaram, e da religião. Por essa razão e para fins de uma melhor apresentação didática, nomeou-se assim as categorias referentes ao suporte social: 1) contexto e formação social e familiar e 2) contexto e formação profissional, complementando e solidificando os achados das pesquisas anteriores.

Os resultados dos trabalhos de Riemer e Chelladurai (1998) explicam que muitos aspectos estão associados à satisfação dos atletas. A performance individual e coletiva, a liderança que o treinador exerce, a coesão da equipe, os aspectos organizacionais e administrativos do clube são fatores que podem aumentar o grau de satisfação dos jogadores. Esses aspectos também foram também ressaltados pelos entrevistados no presente estudo.

Sobretudo, no que se refere à performance individual, os participantes apontaram fatores relacionados ao momento psicológico do atleta no decorrer da partida (Perrault \& Vallerand, 1998). Nesse item, apareceram questões referentes à importância de saber lidar com a alternância no placar, de manter a concentração durante o jogo e de superar seus próprios limites. A motivação, a confiança e a preparação psicológica também estavam presentes no discurso dos participantes. Eles ressaltaram que times que têm maior capacidade de manter um alto nível de concentração, motivação e empenho tendem a ter uma boa performance, em consonância com o que nos dizem Gould e colaboradores (1999). Aspectos como a importância de dar o melhor de si, de sempre fazer o melhor, de lutar por seus objetivos e de ter competência e persistência são freqüentes, sustentando os resultados das pesquisas dos diversos autores citados.

Quando se fala em performance coletiva, os resultados nos mostram a relevância das questões grupais, onde a coesão do time é um fator básico para uma boa performance. $\mathrm{O}$ respeito entre os jogadores possibilita a união do grupo. Dessa forma, nas equipes coesas, os atletas se incentivam para que cada um faça o máximo possível para auxiliar o time em campo conforme Gould e colaboradores (1999). Esse estudo apóia os achados desses autores, acrescentando que é fundamental haver companheirismo e amizade no grupo, sem lugar para disputas por vaidades.

Um aspecto que apareceu como sendo de muita importância nesse estudo foi o papel de líder que o treinador exerce sobre o grupo de atletas. Riemer e Chelladurai (1998) já chamavam a atenção para a maneira como o treinador utiliza a habilidade técnica e tática dos jogadores, seleciona e aplica estratégias de comando apropriadas, treina e instrui os atletas e trabalha individualmente com cada jogador. Os achados desta pesquisa corroboram os resultados desses autores. Evidenciou-se no discurso dos participantes a importância dos jogadores entenderem e assimilarem o método de trabalho do treinador e a importância desse estabelecer metas claras, objetivas, estimulantes e desafiadoras para o grupo. Outro aspecto muito comentado também foi a necessidade de se dar atenção a todos do grupo, treinando-os com a mesma dedicação tanto titulares ou reservas.

Provavelmente a principal colaboração do presente estudo é o destaque dado pelos entrevistados à importância de uma relação afetiva, próxima dos atletas com o treinador. Quando estuda as relações grupais, Zimmermann (1997) atenta para o fato de que se torna fundamental compreender o conceito de liderança, ou mais claramente do que é ser líder, quando se pretende criar uma representação do funcionamento de determinado grupo. Essa afirmação parece se confirmar nesse estudo, em face da importância 
atribuída pelos participantes ao papel do treinador, que representa a figura do líder em um time de futebol. Foi ressaltado que o comandante do grupo deve ter uma relação clara e verdadeira com os atletas, uma boa identificação com seus jogadores, conquistando a simpatia dos mesmos e dando atenção a todos. Além disso, os participantes afirmaram que o treinador deve estar próximo aos atletas no acerto e no erro, proporcionando condições para que eles possam desenvolver seu potencial, sem esquecer de manter a disciplina.

Por fim, observa-se a existência de vários fatores influenciando a performance dos atletas, os quais tanto podem prejudicar ou contribuir para sua satisfação e seu desempenho profissional, nos resultados de suas carreiras e até mesmo em sua saúde mental. Por essa razão, tornase de fundamental importância que as pessoas envolvidas no trabalho com o jogador de futebol estejam atentas a essas questões, provendo as condições necessárias para que o mesmo desempenhe adequadamente o seu exercício profissional. Além disso, é fundamental construirmos conhecimentos relacionados à performance no esporte condizentes com as especifidades culturais e regionais do contexto no qual os atletas estão inseridos (Rubio, 2000). O trabalho desta pesquisa prossegue com a elaboração e validação de um questionário que investiga os fatores relacionados a performance no esporte. Essa escala faz parte do instrumento de um segundo estudo, inserido no projeto maior desta pesquisa (Corrêa, 2002).

\section{Referências}

Brandão, R. M. (1995). Psicologia do Esporte. Em A. F. Neto (Org.), As ciências do esporte no Brasil. (pp. 133-147). Campinas: Autores Associados.

Corrêa, D.K. A. (2002). Avaliação psicológica e performance no esporte. Em R. M. Cruz, J. C. Alchieri \& R. M. C. Sardá Jr. (Orgs.), Avaliação e medidas psicológicas: Produção do conbecimento e da intervenção profissional (pp. 203-223). São Paulo: Casa do Psicólogo.

Corrêa, D. K. A. \& Strey, M. N. (1999). Cidadão ou fonte de alienação: O jogador de futebol em uma análise psicossocial. Revista Psico, 30(2), $129-142$.

Eisler, L. \& Spink, K. S. (1998). Effects of scoring configuration and task cohesionon perception of psychological moment. Journal of Sport \& Exercise Psychology, 14, 177-191.

Gould, D, Guinan, D. Greenleaf, C., Medbery R. \& Peterson, K. (1999). Factors affecting olympic performance: Perceptions of athletes and coaches from more and less successful teams. The Sports Psychology, 13, 371-394.

Hanin, Y. L. (1980). A study of anxiety in sports. Em W. F. Straub (Org.), Sport psychology: An analysis of atblete behavior (pp. 236-249). Ithaca, NY: Mouvement.
Hanin, Y. L. (1986). State and trait anxiety research on sports in the USSR. Em C. D. Spielberg \& S. R. Diaz Guerreo (Orgs.), Cross cultural anxiety (V. 3, pp. 45-64). Washington, DC: Hemisphere.

Hanin, Y. L. (1997). Emotions and athletic performance: Individual zones of optimal functioning. European Yearbook of Sport Psychology, 1, 29-72.

Hardy, L. (1990). A catastrophe model of performance in sport. Em J. C. G. Jones \& L. Hardy (Orgs.), Stress and performance in sport (pp. 81- 106). Chinchesser, England: Wiley.

Hardy, L. (1996) Testing the predictions of the Cusp catastrophe model of anxiety and performance. The Sport Psychology, 10, 140-156.

Jackson, M., Mayochi R. \& Dover, L. (1997). Life after winning gold: II. Journal of Sport \& Exercises Psycholgy, 20, 139-155.

Laville, C. \& Dione, R. (1999). A construção do saber: Manual de metodologia de pesquisa em ciências humanas. Porto Alegre: Artes Médicas.

Less, A. \& Nolan, L. (1998). The biomechanics of soccer: A review. Journal of Sport Science, 211-234.

Matser, J. T. (1999). Neuropsychological impairment in amateur soccer players. Jama., 282 (10) 971-973.

Nideffer, R. (1976). Test of attentional and interpersonal style. Journal of Personality and Social Psychology, 34, 394-404.

Orlick, T. \& Partington, M. (1998). Embracing your potential: Steps to selfdiscovery, balance, and success in sports, work, and life. Champaign, IL, USA: Human Kinetics.

Perreault, S. \& Vallerand, R. J. (1998). Coming from behind: On the effect of psychological moment on sport performance. Journal of Sport \& Exercises Psycholgy, 20, 421-436.

Riemer, H. A. \& Chelladurai, P. (1998). Development of athlete satisfaction questionnaire. Journal of Sport and Exercise Psychology, 20, 127-156.

Rubio, K. (Org.) (2001). Encontros e desencontros: Descobrindo a Psicologia do Esporte. São Paulo: Casa do Psicólogo.

Spielberg, C. D. (1996). Theory and research on anxiety. New York: Academic Press.

Taylor, R. \& Demick, S. (1994). The multidimensional model. Journal of Sport \& Exercises Psychology, 6(1), 51-70.

Vallerand, R. J.\& Colavecchio, P. G. (1988). Psychological moment and performance inferences: A preliminar test of antecedentsconsequences psychological momento model. Journal of Sport \& Exercises Psychology, 10, 93-108.

Venzon, H. (1998). Futebol interativo. Porto Alegre: Mercado Aberto.

Wahl, A. (1997). Historias del fútebol, del juego al deporte. Barcelona: Ediciones.

Weinberg, R. S. \& Gould, D. (2001). Fundamentos da Psicologia do Esporte e do Exercício. Porto Alegre: Artes Médicas.

Williams, J. M. \& Krane, V. (1998). Psychological characteristics of peak performance. Em J. M. Willians (Org.), Applied sport psychology: Personal growth to peak performance (pp. 191-222). Mountain View, CA: Mayfield.

Woodman, T. \& Hardy, L. (1998, outubro). Le stress organisationnel: Une etude de cas. Trabalho apresentado no Journees nationales détudes de la Societe Française de Psychologie du Sport. Poitiers, France.

Zimerman, D. E. (1997). Como trabalhamos com grupos. Porto Alegre: Artes Médicas. 
Sobre os autores

Daniel Kroeff de A. Corrêa é Psicólogo pela Pontifícia Universidade Católica do Rio Grande do Sul. Mestrando em Administração pela Universidade Federal do Rio Grande do Sul.

João Carlos Alchieri é Doutorando, Prof. da Universidade do Vale do Rio dos Sinos e da Universidade Federal do Rio Grande do Sul.

Lúcia Regina Severo Duarte é Doutora em Psicologia, Professora da Pontifícia Universidade Católica do Rio Grande do Sul.

Marlene Neves Strey é Doutora em Psicologia, Coordenadora do Pós-graduação em Psicologia da Pontifícia Universidade Católica do Rio Grande do Sul. 